\title{
Modelo prospectivo de integración en red de la minería a pequeña escala en los procesos de extracción de la roca caliza en el departamento del Cesar
}

Martha Mendoza', Aura de la Victoria ${ }^{2}$

\section{Resumen}

Para realizar esta investigación se tuvieron en cuenta aquellas canteras del departamento del Cesar que se encuentran en la fase de explotación del mineral, cabe resaltar que se trata de aquellas canteras que se encuentran en fase de construcción y montaje, es decir, preparándose para hacer la extracción del mineral. Se investigaron aquellos factores que afecten de forma directa la estructura organizacional y la prospectiva de las pequeñas minas, teniendo como lugar específico el departamento del Cesar. El tipo de minería que más prevalece en el departamento del Cesar es la que se realiza de forma artesanal en pequeños complejos llamados canteras, la cual poco a poco se ha transformado en una actividad económica que genera grandes ingresos a la economía del departamento. En dichas canteras se extrae el material que posteriormente es comercializado, pero desafortunadamente la explotación de los yacimiento se ha dado de forma no organizada, desmedida y de manera artesanal, poco técnica y de forma empírica, lo cual ha generado diversos impactos en los lugares en que se realiza la extracción del mineral, en especial impactos ambientales, los cuales podrían y deberían ser mitigados. Por lo anterior, se logró establecer de manera correcta la actividad en las canteras y la extracción de esta para mejorar su comercialización, como consecuencia a un desorden que se evidencia en la mayoría de las canteras, y la falta de control y vigilancia que existen sobre ellas.

Palabras clave: administración, cantera, comercialización, extracción, minería, prospectiva.

\footnotetext{
'Administradora de Empresas. Docente del programa Ingeniería de Minas de la Fundación Universitaria del Área Andina sede Valledupar. Coordinadora del Semillero Huellas. Correo: mmendoza27/areandina.edu.co

Estudiante de Ingeniería de Minas de la Fundación Universitaria del Área Andina sede Valledupar. Correo: ade20Adestudiantes. areandina.edu.co
} 


\section{Introducción}

Desde hace muchos años la minería se ha convertido en una de las principales actividades económicas del departamento del Cesar, esto debido a la gran utilidad que pueden representar los minerales que se encuentran en los territorios de dicho departamento; con el pasar del tiempo el auge de la minería ha incrementado y, gracias a esto, muchas personas del departamento del Cesar han podido mejorar su calidad de vida, ya que la minera proporciona una gran fuente de trabajo y ha permitido un gran flujo económico para la región del Cesar.

De igual forma, el tipo de minería que más prevalece en el departamento del Cesar es la que se realiza de forma artesanal en pequeños complejos llamados canteras. En las canteras de caliza se extrae el material que posteriormente es comercializado, pero desafortunadamente la explotación de los yacimientos se ha dado de forma no organizada, desmedida y de manera artesanal, poco técnica y de forma empírica, lo cual ha generado diversos impactos en los lugares en que se realiza la extracción del mineral, en especial impactos ambientales, los cuales podrían y deberían ser mitigados.
Pero esto solo se podría lograr si se establecieran de manera correcta la actividad en las canteras de caliza, como consecuencia a un desorden que se evidencia en la mayoría de las canteras y a la falta de control y vigilancia que existe sobre ellas; la prospectiva que se generan a un mediano plazo no es la mejor. Las canteras de caliza del departamento pudieran generar más y mejores recursos con menos impactos si se realizara con una mejor organización y un mejor orden.

En el marco del desarrollo de la minería a pequeña escala en el departamento del Cesar la presente investigación será de gran utilidad porque es una propuesta innovadora que contribuirá a una mejora en la calidad de trabajo y de vida para las personas que laboran en las canteras y, a su vez, una mejor organización como empresa; de igual forma, tendrá un gran impacto a mediano y largo plazo, permitiendo generar una mejor prospectiva de la minería y mejorando directamente la calidad del trabajo en las pequeñas minas que es la mejor contribución que puede aportar este proyecto, el cual afecta directamente la economía y la productividad del departamento.

Desde el punto de vista social, el modelo propuesto será contextualizado 
con base en la necesidad de inducir aproximaciones hacia el desarrollo sostenible, desde el ámbito académico; bajo premisas inspiradas en un enfoque prospectivo, teniendo en cuenta como vértice la articulación entre Estado- Universidad-Sociedad para los procesos de planeación, ejecución, evaluación y control de la gestión de la cooperación en red de las mismas. (España, 2012)

Adicionalmente, por ser un tema novedoso en el contexto organizacional colombiano, los resultados que se obtengan, al igual que el modelo prospectivo que se genere, servirá para futuras publicaciones e investigaciones sobre prospectiva en la integración de redes.

Desde el punto de vista práctico, esta investigación presentara un aporte, principalmente para las canteras, articulado con la comunidad y el gobierno, ya que se dan los primeros pasos en la propuesta de un modelo prospectivo de integración en red en las canteras de minería a pequeña escala en el departamento del Cesar que permita el mejoramiento de un sistema global que involucre las diferentes unidades de análisis.

La investigación planteada presenta en sí misma valor metodológico expresado mediante el propio desarrollo de las canteras, así como de los planteamientos propuestos, estructurado en un método general caracterizado por una estructura de apropiada organización, economía, política social y de integración en la solidaridad de los mismos actores.

\section{Materiales y métodos}

El tipo de investigación que se realizará es cuantitativa, estudios descriptivos y exploratorios con una población de 370 canteras y una muestra probabilística de las canteras que se encuentran en fase de explotación, los datos serán recolectados mediante inspecciones en sitio y encuestas.

\section{Población}

La población de estudio para la realización de la presente investigación serán las canteras o minas a pequeña escala en el departamento del Cesar, entre las cuales se encuentran canteras de caliza que contribuyen positivamente a la economía del departamento. 


\section{Técnica e instrumento de procesamiento de los datos}

La técnica que será utilizada para realizar el procesamiento de los datos será la observación de campo directa y la realización de encuestas, las cuales serán procesadas mediante la utilización de la herramienta computacional Excel.

\section{Procedimiento diseño y de la investigación}

Para poder realizar el desarrollo de esta propuesta investigativa se llevarán a cabo las etapas a continuación:

- Revisión de antecedentes.

- Recolección de datos.

- Análisis de datos por medio de estudios observatorios, descriptivos y un análisis estadístico de la información, utilizando como herramienta computacional Excel e interpretación de datos.

- $\quad$ Entrega de informe final

\section{Descripción y desarrollo del proyecto}

En el marco del desarrollo de la minería a pequeña escala en el departamento del Cesar, el presente proyecto será de gran utilidad, ya que la propuesta de una red de canteras en el departamento es una propuesta innovadora y que contribuirá a que se mejoren la calidad de trabajo en las canteras y una mejor organización como empresa, de igual forma tendrá un gran impacto a mediano y largo plazo, permitiendo generar una mejor prospectiva de la minería y mejorando directamente la calidad del trabajo en las pequeñas minas que es la mejor contribución que puede hacer este proyecto, el cual afecta directamente la economía y la productividad del departamento.

\section{Resultados}

Los resultados obtenidos en el primer momento de la investigación siguen el mismo orden en que fueron recogidos y como se presentan en el diseño de la metodología. Se obtuvieron bases de datos con información de títulos vigentes obtenidos del ANLA (2014), se llevó a cabo la delimitación oportuna de la información y, posteriormente, se obtuvieron los siguientes resultados. 


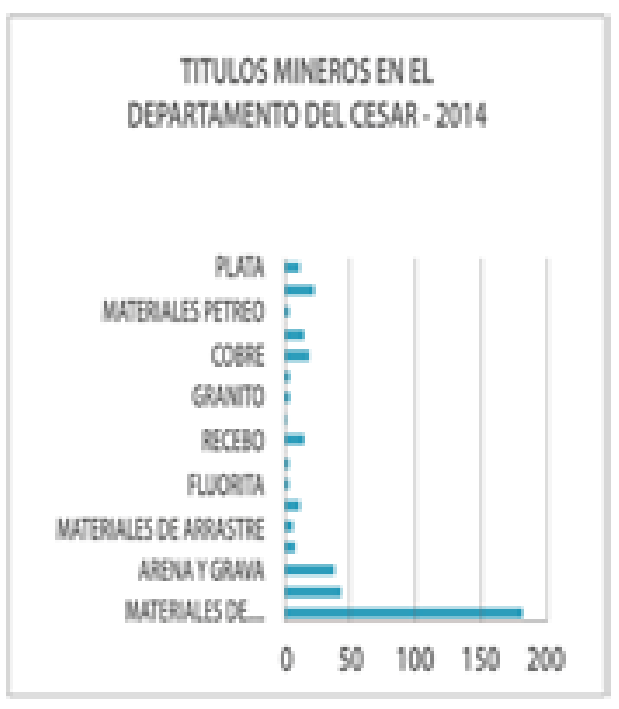

Figura 1. Títulos mineros en el departamento del Cesar 2014

Fuente: elaboración propia (2017) con base en ANLA (2014).

Se pueden inferir de la gráfica 1 aspectos fundamentales como lo son la variedad de áreas de influencias con títulos de concesiones para explotar, de igual forma, la importancia que recae en la utilización de materiales de construcción en el departamento del Cesar, ya que consta de 370 títulos aprobados, distribuidos en materiales de construcción con 182 títulos, la arcilla con siete títulos, la fluorita con dos títulos, asfalto con un título, cobre con 18 títulos, oro con 21 títulos, caliza con 43 títulos, el material de arrastre con seis títulos, balastro con dos títulos, granito con dos títulos, hierro con nueve títulos, arena y grava con 37 títulos, barita con once títulos, recebo con catorce títulos, vanadio con dos títulos y los materiales pétreos con dos títulos.

La extracción de la minería a pequeña escala es de manera artesanal, las cuales conllevan a beneficiar económica, social y ambientalmente la población que se está viendo afectada por la explotación de este material. Por lo anterior, se deduce que, una de las características comunes es la explotación de depósitos marginales o pequeños, la carencia de capital y el trabajo intensivo con bajos índices de recuperación.

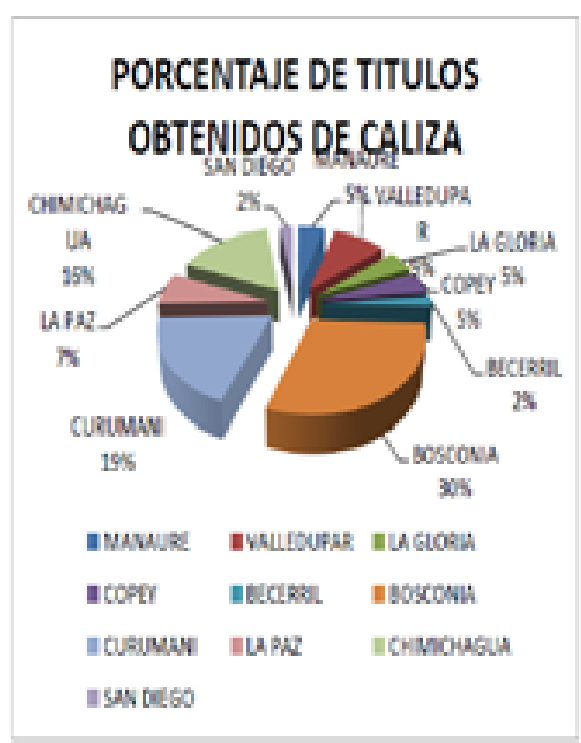

Figura 2. Porcentaje de títulos obtenidos de Caliza Fuente: elaboración propia (2017) con base en ANLA (2014). 
En términos de porcentajes de caliza, se establece que existen alrededor de 43 títulos mineros, de los cuales existe un mayor porcentaje en el municipio de Bosconia, con un 30\% de títulos obtenidos, un $19 \%$ en Curumaní y el restante ubicado en los municipios de La Paz, Chimichagua, San diego, Manaure, Valledupar, La Gloria, El Copey y Becerril. López (2010),

establece que la caliza es una roca sedimentaria porosa de origen químico, formada mineralógicamente por carbonatos de calcio. Cuando se calcina da lugar a la cal. Su textura es granular fina o gruesa, es un poco rasposa. La roca caliza nos muestra la edad de la tierra a través de su gran contenido de fósiles.

Cabe resaltar que la explotación de yacimientos de caliza es de manera rudimentaria, ya que utilizan maquinarias como el martillo, el hilo dentado, sepa- radores, picos, palas, entre otros, para la obtención del material.

Es por esto que su proceso de transformación y obtención de productos derivados, ha permitido el desarrollo de diversas regiones, debido a su aplicación como materia prima del cemento, lo que la posiciona como un material clave en el sector de la construcción. (López, 2010)

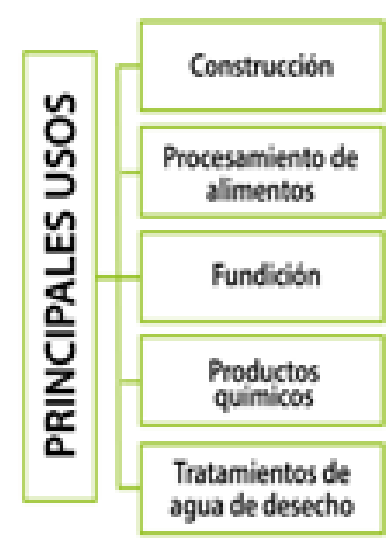

Figura 3. Principales usos de la roca caliza Fuente: López (2010) y Victoria (2015). 